\title{
Cardápios e sustentabilidade: ensaio sobre as diretrizes do Programa Nacional de Alimentação Escolar
}

\author{
Menus and sustainability: Essay on the \\ guidelines of the National School \\ Food Program
}

Anete Araújo de SOUSA ${ }^{1}$

Ana Paula Ferreira da SILVA ${ }^{2}$

Elaine de AZEVEDO ${ }^{3}$

Mariana Oliveira RAMOS ${ }^{4}$

RE S U M O

O Programa Nacional de Alimentação Escolar é uma das políticas públicas brasileiras que têm estabelecido estreito diálogo com os princípios da Política Nacional de Segurança Alimentar e Nutricional e da Agroecologia. Diretrizes de execução, alinhadas com a temática da sustentabilidade, foram estabelecidas pela Lei n 11.947 , promulgada em julho de 2009, que estipula recursos para a compra de alimentos produzidos pela agricultura familiar, preferencialmente orgânicos, revelando preocupações ambientais e sociais, voltadas ao desenvolvimento da economia local. Este artigo objetivou refletir sobre a elaboração do cardápio instituído nas diretrizes de execução do Programa, com ênfase nos elementos que podem indicar a alimentação escolar como promotora de sistemas alimentares ecológicos e de desenvolvimento local sustentável. Ressalta-se que, apesar do avanço das diretrizes, é necessário fortalecer estratégias para resgatar hábitos alimentares e produzir alimentos compatíveis com tais diretrizes, além de planejar cardápios que contemplem a diversidade e sazonalidade de alimentos regionais e o mapeamento de agricultores ecológicos para nortear a demanda e a oferta programadas. A gestão da compra e da logística, assim como o apoio governamental ao Programa e o controle social por parte da comunidade escolar, além da sensibilização e educação continuada de técnicos e profissionais da área de alimentação escolar, são fundamentais para que os cardápios escolares dialoguem com a sustentabilidade.

${ }^{1}$ Universidade Federal de Santa Catarina, Centro de Ciências da Saúde, Departamento de Nutrição. Campus Universitário, Sala n 205, Trindade, 88040-970, Florianópolis, SC, Brasil. Correspondência para/Correspondence to: AA SOUSA. E-mail: <anete.sousa@ufsc.br>.

${ }^{2}$ Universidade Federal de Santa Catarina, Centro de Ciências da Saúde, Programa de Pós-Graduação em Nutrição. Florianópolis, SC, Brasil.

${ }^{3}$ Universidade Federal do Espírito Santo, Centro de Ciências Humanas e Naturais, Programa de Pós-Graduação em Ciências Sociais. Vitória, ES, Brasil.

${ }^{4}$ Universidade Federal do Rio Grande do Sul, Programa de Pós-Graduação em Desenvolvimento Rural, Faculdade de Ciências Econômicas. Porto Alegre, RS, Brasil. 
Experiências exitosas e pesquisas com base na análise dessas diretrizes devem ser incentivadas, para possibilitar o fortalecimento do Programa.

Palavras-chave: Agricultura sustentável. Alimentação escolar. Fidelidade a diretrizes. Planejamento de cardápio. Segurança Alimentar e Nutricional.

\section{A B S T R A C T}

The National School Food Program is one of the Brazilian public policies which has established an intimate dialog with the principles of the National Food and Nutrition Security Policy and Agroecology. Execution guidelines aligned with the theme of sustainability were established in the program via Law $n^{\circ} 11.947$, enacted in July 2009, which stipulates resources for the purchasing of food (preferentially organic) produced by family farms, demonstrating environmental and social concerns as well as those related to the development of the local economy. The aim of this paper is to reflect on the theme of menu design incorporated in the execution guidelines of the School Food Program with emphasis on the elements that can highlight school meals as a promoter of ecological food systems and local sustainable development. It is noted that despite the advance represented by the guidelines, there is a need to strengthen the strategies to recover food habits and for the production of foods compatible with these guidelines, along with actions related to menu planning considering the diversity and seasonality of regional food products and the mapping of ecological farmers to guide the programmed demand and supply of these products. The management of the purchasing and logistics, government support of the program and its social control by the school community, along with constant raising of awareness and training for professionals acting in the area of school meals are fundamental for school meals to enter a dialog with sustainability. Successful experiences and research based on the analysis of these guidelines should be encouraged to enable the strengthening of the program.

Keywords: Sustainable agriculture. School feeding. Guideline adherence. Menu planning. Food security. Nutrition programs and policies.

\section{N T R O D U ÇÃ O}

O Programa Nacional de Alimentação Escolar (PNAE) é uma das políticas públicas fundamentadas no direito dos escolares à alimentação saudável e adequada ${ }^{1,2}$, em consonância com a discussão da sustentabilidade na Nutrição e com os princípios da Política Nacional de Segurança Alimentar e Nutricional (PNSAN) ${ }^{1,2}$. Dentre as diretrizes da PNSAN, destacam-se a conservação da biodiversidade, a utilização sustentável dos recursos na produção de alimentos, a promoção da agricultura familiar e das práticas de Agroecologia, além da garantia da qualidade biológica, sanitária, nutricional e tecnológica dos alimentos ${ }^{3}$.

A partir de julho de 2009, o Fundo Nacional para o Desenvolvimento da Educação (FNDE) regulamentou que, no mínimo, 30\% do total de recursos repassados aos Estados e Municípios para a gestão do PNAE sejam destinados à compra de alimentos da agricultura familiar, preferencialmente orgânicos. A compra desses alimentos deve respeitar a produção local, regional ou nacional, exatamente nessa ordem ${ }^{4,5}$.

A elaboração dos cardápios constitui a principal ação, ligada efetivamente à alimentação escolar, que pode ir ao encontro de tais diretrizes. Para tanto, necessita levar em consideração elementos que envolvem desde a produção de alimentos até a distribuição das refeições.

As formas de gestão, execução e composição dos cardápios passaram por uma série de mudanças desde a criação do PNAE em 1955'. Com as atuais regulamentações, o apoio à agricultura familiar é compatível com a promoção de práticas alimentares saudáveis ${ }^{6}$, pelo estímulo ao consumo de alimentos in natura e pela utilização de alimentos regionais que promovam a sociobiodiversidade 4,5,7. A própria Política de Segurança Alimentar e Nutricional (SAN) e a de Promoção da Saúde, assim como o Plano Nacional de Promoção das Cadeias de Produtos da So- 
ciobiodiversidade, ressaltam a relação entre a alimentação adequada e saudável e os sistemas de produção de alimentos sustentáveis, incorporando valores socioambientais e culturais, ${ }^{6,7}$.

Todavia, a implantação de tais diretrizes que dialogam com a promoção da sustentabilidade ainda é um processo recente e, no Brasil, ainda são escassos os estudos sobre os cardápios escolares, a SAN e a sustentabilidade, bem como os estudos sobre a avaliação do cardápio para o PNAE e suas implicações para o desenvolvimento sustentável.

Diante dessas considerações, este artigo tem por objetivo discutir a elaboração do cardápio, no conjunto das diretrizes de execução do PNAE, com ênfase nos elementos que destacam a alimentação escolar como promotora do desenvolvimento local sustentável. A temática abrange diferentes aspectos que dialogam com a SAN, a sustentabilidade e a capacidade do PNAE de promover o fortalecimento de sistemas alimentares baseados nos princípios da Agroecologia.

Inicialmente, são apresentadas as diretrizes de elaboração do cardápio com base no histórico do PNAE. Em seguida, é discutida a sustentabilidade na Nutrição, tema central do artigo, cujas premissas têm influenciado as mudanças estruturais no PNAE. O artigo finaliza com reflexões sobre os desafios da elaboração de cardápios para a alimentação escolar, apontando novas questões de pesquisa.

\section{Elaboração do cardápio no contexto histórico do Programa Nacional de Alimentação Escolar}

A alimentação escolar, desde sua criação, em 1955, passou por uma série de modificações. Originalmente, a oferta de alimentos aos escolares apresentou estreita relação com o problema da fome e da desnutrição, com uma perspectiva intervencionista e paternalista, desconsiderando as questões estruturais do problema. Os produtos do Programa eram, em grande parte, doados para a região Nordeste pelo Fundo Internacional de Socorro à Infância (FISI), atual United Nations Children's Fund (Unicef), e para as demais regiões pela United States Agency International Development (USAID). Até o início da década de 1970, a ajuda alimentar veio da Organização das Nações Unidas (ONU) e da Commodity Credit Corporation, responsáveis pela doação de leite em pó. Essas doações tinham o objetivo de escoar a produção excedente de leite do Canadá e dos Estados Unidos ${ }^{8}$.

A partir da década de 1970, o governo brasileiro assumiu a oferta de produtos para a alimentação escolar, incentivando a instalação de indústrias alimentares para atender à demanda. A gestão do Programa era centralizada e, portanto, a elaboração do cardápio, a aquisição dos gêneros alimentícios, o controle de qualidade e a distribuição dos alimentos eram responsabilidade do Ministério da Educação'. O uso de produtos formulados nos cardápios era predominante ${ }^{9,10}$.

Na análise de Abreu"1, a história da alimentação escolar no Brasil foi marcada pelo desrespeito aos hábitos alimentares regionais, pela prática de padronização alimentar e pelo clientelismo e favorecimento a grupos econômicos, em detrimento dos pequenos agricultores e dos alimentos frescos e locais. Além disso, o Programa era marcado por episódios frequentes de denúncias de corrupção e desvio de verbas, apurados pelo Tribunal de Contas da União (TCU). Diante dessa realidade, a descentralização foi insistentemente defendida.

A discussão do direito à alimentação escolar teve início com a promulgação da Constituição Federal de 1988. No mesmo período, iniciou-se o processo de descentralização do PNAE. Entretanto, somente em 1994, com a Lei no 8.913, a execução do Programa foi transferida aos Estados, Distrito Federal e Municípios'.

Galeazzi \& Chaim $^{10}$, Abreu ${ }^{11}$ e Galeazzi et al. ${ }^{12}$ destacam que esse processo impactou o Programa com diferentes repercussões positivas, como: utilização de cardápios mais variados; diversificação dos gêneros alimentícios adquiridos; 
inserção de alimentos regionais; maior diversificação de alimentos locais; efetiva participação da comunidade; e fomento a dinâmicas de controle social e integração entre alimentação e práticas pedagógicas com vista à formação de hábitos alimentares saudáveis.

Spinelli \& Canesqui ${ }^{9}$ e, mais recentemente, Belik \& Chain ${ }^{13}$ e Real \& Schneider ${ }^{14}$ concluíram que a descentralização do PNAE não apenas deu impulso e credibilidade à política da alimentação escolar, como incentivou a produção da agricultura familiar local e favoreceu a aproximação dos cardápios da realidade de cada região.

As últimas resoluções do PNAE ${ }^{4,5}$ determinam que sejam priorizados alimentos orgânicos e/ou ecológicos na compra dos alimentos da agricultura familiar e, também, que as ações de Educação Alimentar e Nutricional (EAN) ${ }^{4}$ estimulem a utilização de produtos orgânicos e/ou ecológicos e promotores da sociobiodiversidade.

A Resolução n 38 do FNDE, datada de julho de 2009, estipula que as refeições oferecidas na escola devem cobrir de 20 a $70 \%$ das necessidades nutricionais diárias dos escolares. As recomendações variam conforme a categoria de atendimento (creche, pré-escola, ensino fundamental e Educação de Jovens e Adultos), a faixa etária (de 7 meses a 60 anos), a presença de necessidades nutricionais específicas e o período de permanência na escola (parcial ou integral). São definidas ainda recomendações e limites para o atendimento médio das necessidades nutricionais dos escolares ( $10 \%$ da energia total proveniente de açúcar simples de adição, 15 a 30\% da energia total proveniente de gorduras totais, 10\% de gordura saturada, $1 \%$ de gordura trans e $1 \mathrm{~g}$ de sal) $)^{4}$.

Em relação à Resolução $n^{\circ} 38$ (julho de $2009^{4}$, a Resolução n 26 do FNDE (junho de $2013)^{5}$ passa a estipular necessidades nutricionais diárias e altera algumas recomendações anteriores, como a quantidade de sódio utilizadas no cardápio, a oferta de doces (limitada a duas porções/semana) e o número de refeições, dentre outras. Além disso, também estabelece a defi- nição de horários e alimentos adequados a cada tipo de refeição, procurando considerar a cultura alimentar local e a diferenciação da porção conforme a faixa etária, as necessidades nutricionais, as características específicas (intolerâncias, alergias) e as peculiaridades etnoculturais. Outra exigência é a inserção de fichas técnicas de preparo e informação nutricional, respeitando o direito à informação alimentar.

O Programa Nacional de Alimentação Escolar assumiu ainda, como premissa, os critérios restritivos incorporados ao cardápio, que colocam em evidência a intervenção do Estado no resgate de hábitos saudáveis, ao priorizar alimentos frescos e in natura, em detrimento de produtos processados. Há restrições ao uso de enlatados, embutidos, doces, alimentos compostos, preparações prontas ou semiprontas, alimentos concentrados (em pó ou desidratados para reconstituição), alimentos com quantidade elevada de sódio ou gordura saturada, e bebidas com baixo teor nutricional. Por fim, deve-se garantir a oferta de, pelo menos, três porções de frutas e hortaliças por semana (200 g/aluno/semana) nas refeições ${ }^{4,5}$.

Com base nas análises da Pesquisa de Orçamentos Familiares (POF) e nas diretrizes do Guia Alimentar da População Brasileira, Téo \& Monteiro ${ }^{15}$ propõem a oferta de, no mínimo, uma porção de frutas e hortaliças por refeição na escola, e estabelecem uma proporção entre alimentos de três grupos. O grupo 1 é composto por cereais, leguminosas, hortaliças, tubérculos, frutas, leite, ovos, carnes e alimentos minimamente processados. Já o grupo 2 inclui alimentos utilizados como ingredientes culinários, como óleos, gorduras, farinhas, féculas e açúcar. Por fim, o grupo 3 engloba produtos elaborados com ingredientes do grupo 2, com pouca ou nenhuma quantidade daqueles do grupo 1. Os autores propõem uma proporção de 3:1 entre os grupos 1 e 2, e que o grupo 3 não ultrapasse 15\% do total calórico da refeição.

Conforme as análises de Triches \& Schneider ${ }^{16}$, a recente obrigatoriedade da compra de alimentos provenientes da agricultura familiar, 
para a alimentação escolar, é uma das estratégias que aproximam o agricultor familiar e os gestores, criando a possibilidade da produção, consumo e comércio local de alimentos.

Não se discute que os cardápios escolares devem contemplar características como acessibilidade física e financeira, além de sabor, variedade, cor, harmonia e segurança sanitária ${ }^{17}$. Porém, além desses atributos, os cardápios em consonância com a SAN incorporam a segurança química dos alimentos (com foco para os agrotóxicos e outros contaminantes da agropecuária convencional) e exigem a opção por modelos produtivos, que considerem a finitude dos recursos naturais e a importância do agricultor na produção de alimentos, aproximando-se, desse modo, da abordagem da sustentabilidade na Nutrição.

Apesar do cenário positivo e inovador do atual Programa, ainda é necessário um aprofundamento sobre o tema dos cardápios, atrelado a práticas sustentáveis que levem em conta a dimensão socioambiental e cultural da alimentação. Tal abordagem, discutida por Azevedo \& Rigon ${ }^{18}$, será apresentada a seguir.

\section{A sustentabilidade no campo da alimentação e nutrição}

A ideia de desenvolvimento sustentável aparece como contraposição à visão economicista de desenvolvimento do século 19, que privilegiava o crescimento econômico e a industrialização como sinônimos de desenvolvimento, desconsiderando o caráter finito dos recursos naturais e a diversidade dos atores sociais. O termo desenvolvimento sustentável foi criado a partir das discussões sobre Ecodesenvolvimento, com Maurice Strong, e difundido pelo economista Ignacy Sachs, na década de $1970^{19}$.

Em 1983, a Comissão sobre Meio Ambiente e Desenvolvimento (UNCED) da ONU, produziu um documento intitulado "Nosso Futuro Comum". O documento, publicado em 1987, definiu o desenvolvimento sustentável como "um novo caminho de progresso social, ambiental e econô- mico que procura atender às aspirações do presente sem comprometer a possibilidade de atendê-las no futuro" 20 .

Para Morais \& Costa ${ }^{21}$, após a Conferência das Nações Unidas para o Meio Ambiente e Desenvolvimento/Rio 92, outras dimensões da sustentabilidade foram incorporadas à proposta original, com especial destaque para a dimensão cultural e a participação e controle sociais, aliadas à discussão do local como um espaço privilegiado de construção de cidadania, processo civilizatório e promoção da saúde e da sustentabilidade.

Ressalta-se que, apesar das evidências que fortalecem as críticas ao sistema agroalimentar moderno, estimulando debates e experiências locais/regionais de contraposição desde os anos 1980, o cenário atual é de disputa também no âmbito da "sustentabilidade". O termo foi incorporado por diferentes instituições, e manejado por interesses nem sempre altruístas. Uma forma de posicionar-se frente à polissemia do termo é firmar a concordância com quatro pilares da sustentabilidade: econômica, ecológica, social e cultural22. $^{22}$.

Entretanto, o que interessa centralmente a este artigo é discutir a Nutrição sob a ótica da sustentabilidade. Para tanto, a Nutrição flexibiliza suas fronteiras disciplinares e incorpora um olhar sobre a propriedade agrícola.

O sistema agroalimentar moderno, comumente chamado de convencional, tem como foco a alta produtividade e a consequente subordinação de agricultores a empresas detentoras de tecnologia agrícola. Tal sistema prioriza a monocultura, o uso de insumos sintéticos em larga escala, a comercialização em grandes redes varejistas e a venda para exportação. Além de se mostrar descompromissado com o direito humano a uma alimentação adequada e saudável, esse sistema tem gerado crises sucessivas, com repercussões sociais, culturais, ambientais e, ainda, sobre a saúde humana, discutidas por diferentes autores ${ }^{18,23,24}$. Torna-se evidente que os processos de produção, transformação, circulação, comercialização e consumo necessitam de uma ressigni- 
ficação, inserida em uma outra lógica, que se afaste da influência neoliberal que rege o modelo.

Como alternativa, surge a perspectiva da sustentabilidade da Nutrição, o que implica fomentar um sistema agroalimentar ecológico, garantir acesso à terra e aos meios de produção, viabilizar as condições de reprodução social da agricultura familiar e a ideia de um mundo rural como patrimônio da sociedade, extrapolando, assim, o enfoque da produtividade agropecuária ${ }^{19}$.

Esse apelo se aproxima do movimento sociopolítico da Agroecologia, que se caracteriza como uma proposta de fortalecimento do agricultor em busca de sua identidade, de suas raízes culturais e, principalmente, de sua autonomia e participação ativa no processo produtivo, favorecendo o local como foco de ação. Constitui-se como um campo do conhecimento científico com potencial para apoiar a transição dos atuais modelos de agricultura convencional para modelos de sistemas agroalimentares sustentáveis, que tenham como princípios a dignificação do agricultor familiar e a conservação do meio ambiente, a partir de ações sociais coletivas de caráter participativo 25,26 .

O momento atual levanta, sobremaneira, o tema da qualidade dos alimentos, amparado pela problemática ambiental, de saúde humana e de justiça social. Dentro desse enfoque, o próprio conceito de alimento saudável e de qualidade alimentar supera as premissas de alimento com valor nutricional quantitativamente equilibrado, na medida em que incorpora dimensões socioambientais e sofre a influência das diretrizes das Políticas Nacionais de Segurança Alimentar e Nutricional e da discussão sobre sustentabilidade na Nutrição ${ }^{6,19}$

No campo dos estudos agroalimentares, especialistas têm-se dedicado a discutir experiências agroecológicas, circuitos curtos de comercialização, organização de consumidores, multifuncionalidade da agricultura e do mundo rural, economia solidária e comércio justo, certificação participativa e marcas coletivas de alimentos orgânicos ou tradicionais, dentre outros temas, agrupados em estudos sobre redes alimentares alternativas ou contramovimentos alimen$\operatorname{tares}^{27,28}$.

A busca da sustentabilidade no campo agroalimentar tem apontado a importância da reconexão (no contexto europeu) e da revalorização (no contexto brasileiro) ${ }^{29,30}$. Isso porque, para $\mathrm{Cruz}^{30}$, no Brasil, ao contrário dos países europeus, ainda é possível encontrar grande diversidade de práticas agrícolas e alimentares tradicionais. A revalorização pressupõe o reencontro de consumidores com produtores, bem como o reconhecimento da qualidade ampla dos produtos oriundos da agricultura familiar e da sociobiodiversidade. Para que tal processo ocorra, tem-se debatido a importância de se ampliar o acesso a tais alimentos ${ }^{30}$.

A emergência da sociobiodiversidade nos espaços de debate sobre o desenvolvimento no país é um sinal claro dessa permanência, assim como a inserção da perspectiva da sustentabilidade e da Agroecologia nas Políticas de Alimentação e Nutrição, incluindo o PNAE.

As novas diretrizes do PNAE, ao exigirem que os alimentos sejam comprados de agricultores familiares e ao orientarem a preferência por alimentos orgânicos ou ecológicos, representam potencial avanço na consolidação da Agroecologia e dos sistemas agroalimentares sustentáveis no Brasil, com base na ação local. Cumprindo essas diretrizes, o Programa também exerce um importante papel no fortalecimento das premissas do desenvolvimento rural sustentável e no acesso a alimentos saudáveis e adequados, de acordo com as premissas da PNSAN.

\section{Cardápios e sustentabilidade na alimentação escolar}

A concepção da sustentabilidade no campo da alimentação e nutrição está em processo de construção e se configura como um dos grandes desafios do nutricionista quando da 
elaboração dos cardápios na alimentação escolar. Sua regulamentação define a incorporação de alimentos in natura, diversificados e sazonais, respeitando preferências, hábitos e tradições alimentares locais ${ }^{4,5}$, não se limitando a especificações padronizadas sobre as características sensoriais dos alimentos nos processos de compra.

As condições tropicais do Brasil possibilitam uma produção diversificada de alimentos, que contrasta com a tendência de se oferecerem cardápios baseados em quatro ou cinco hortaliças (tais como alface, cebola, tomate, batata e cenoura). Essas culturas utilizam grandes quantidades de agrotóxicos ${ }^{31}$, são responsáveis por graves impactos à saúde do produtor e do consumidor, e ajudam a promover a erosão cultural e a contaminação dos recursos naturais ${ }^{32}$.

Os processos de erosão cultural da alimentação das populações têm relação com a modernização na produção de alimentos. Mudanças na composição dos cardápios de famílias de agricultores são uma das evidências.

Ramos $^{33}$ registrou modificações nas práticas alimentares de famílias rurais, que podem ser resumidas pelo abandono ou redução do consumo de alimentos locais, como milho, tubérculos, banha de porco e frutas nativas, e pelo aumento do consumo de sucos em pó, óleo de soja, margarina, farinha de trigo e outros alimentos industrializados.

Menasche et al. ${ }^{34}$, ao analisarem etnografias de mudanças alimentares entre famílias de agricultores do Vale do Taquari (RS), descrevem o estranhamento dos jovens frente a alimentos que faziam parte rotineira das receitas de seus avós (como o milho, o inhame, embutidos e algumas preparações à base de leite). As autoras referem-se ao fenômeno como a "conquista do paladar" dos agricultores, demonstrando a extensão de processos de erosão cultural mencionados.

Em Belém (PA), município com forte tradição indígena, alimentos como farinhas de mandioca, frutos do mar e frutas da região (açaí, maracujá, mamão, abacaxi, pupunha, cupuaçu, coco, bacuri, cupuaçu e outras) não foram encontrados na alimentação das escolas ${ }^{35}$.

Essas poucas análises reforçam a tendência de padronização dos hábitos alimentares, em cardápios monótonos e desprovidos de referência local, em contraposição às infinitas possibilidades que os biomas brasileiros e suas populações apresentam quanto à diversidade de alimentos e às maneiras de prepará-los.

Os cultivos, os alimentos e suas formas de preparo carregam diferentes sentidos e variam de acordo com a cultura de cada grupo social, a qual orienta os saberes e práticas alimentares ${ }^{36}$.

A escola é um espaço de pesquisa permanente nas comunidades rurais e urbanas, e pode também ser um espaço de reconhecimento de identidades locais enfraquecidas pelo processo de modernização da agricultura, da comida e das vidas de cada comunidade ${ }^{37}$. Nesse sentido, a inserção de alimentos agrobiodiversos na alimentação escolar, como as diferentes variedades de cereais e legumes crioulos ${ }^{38}$ (a exemplo do milho verde e das morangas), os tubérculos (aipim, inhame, cará, araruta) e as hortaliças espontâneas nos cardápios escolares, é entendida como um dos aspectos promotores da sustentabilidade, relacionando-se com o resgate e a valorização cultural, bem como com o fortalecimento de sistemas alimentares de base agroecológica ${ }^{39}$.

Na Mata Atlântica, bioma que abriga os estados do Sul do País, há, por exemplo, dezenas de frutas nativas com grande valor nutritivo e potencial de produção em sistemas agroflorestais e agroecológicos, como o açaí de juçara, a guabiroba, o butiá, a jabuticaba e o araçá, dentre outras. As polpas de frutas nativas - que podem ser usadas para sucos, vitaminas, bolos e outras preparações nas escolas -, são exemplo de alimentos pouco processados, com bom valor nutritivo e estratégicos para a consolidação de cadeias produtivas de interesse socioambiental7 ${ }^{7,37}$.

O Plano Nacional de Promoção das Cadeias de Produtos da Sociobiodiversidade ${ }^{7}$ destaca que a expansão dos hábitos alimentares com 
produtos regionais, a produção em sistemas agroecológicos e a inclusão dos alimentos sociobiodiversos nos cardápios de políticas públicas de alimentação e nutrição são ações fundamentais para promover o desenvolvimento sustentável no Brasil. E o PNAE é um instrumento importante para a viabilização dessas ações.

Organizações do movimento agroecológico têm buscado consolidar essa conquista. Uma sistematização de experiências de promoção da SAN elaborada pela Articulação Nacional de Agroecologia (ANA) apontou a abertura do mercado institucional para a absorção dos alimentos ecológicos provenientes da agricultura familiar como uma das principais questões inovadoras, representando um avanço no caminho da intersetorialidade, necessária para a efetividade das ações em $\operatorname{SAN}^{39}$.

Um relato de experiências do envolvimento da agricultura familiar com a alimentação escolar, na perspectiva da SAN, destacou como resultado positivo a diversificação dos cardápios com alimentos in natura característicos da região. Nessa experiência descrita por Ramos ${ }^{40}$, os cardápios escolares começaram a ofertar, já no primeiro ano de implantação da Lei $n^{\circ} 11.947$, maior quantidade, qualidade e regularidade de frutas e hortaliças.

Por fim, a discussão da sustentabilidade na preparação de alimentos envolve ainda outros aspectos, tais como: a prática de separação e tratamento de resíduos orgânicos, recicláveis e óleo de fritura; a minimização do uso de embalagens plásticas na compra de alimentos; a priorização de produtos de limpeza biodegradáveis; e a seleção criteriosa de utensílios, equipamentos, instalações hidráulicas e elétricas ${ }^{41,42}$.

\section{Desafios para elaboração de cardápios do Programa Nacional de Alimentação Escolar: novas questões de pesquisa}

A recente diretriz do PNAE pode representar, de fato, uma importante conquista e o reconhecimento dessa política como estratégia de SAN e como pilar de desenvolvimento rural sustentável no país.

Apesar do avanço da regulamentação, e além desses desafios estruturais de promover a sustentabilidade no campo da alimentação e nutrição, há ainda aqueles concernentes à composição de cardápios.

A Resolução n²6, de junho de 2013, ressalta que o percentual de $30 \%$ poderá ser dispensado em situações de "inviabilidade de fornecimento regular e constante dos gêneros alimentícios, desde que respeitada a sazonalidade dos produtos" ${ }^{5}$ (p.12). Este último destaque, em relação à legislação anterior, pode ser considerado um avanço na regulamentação, pois a oferta de alimentos orgânicos e ecológicos pode ficar inviabilizada se os cardápios não forem planejados junto com os agricultores para programar a oferta, uma vez que uma das características desses alimentos é respeitar a sazonalidade das diferentes culturas.

O Ministério de Desenvolvimento Agrário destaca ações que podem fortalecer o diálogo entre os responsáveis pela elaboração do cardápio e os responsáveis pela produção de alimentos sustentáveis, contribuindo para garantir o abastecimento de alimentos orgânicos. Dentre tais ações, incluem-se o mapeamento dos produtos da agricultura familiar local e o respeito à diversidade e à sazonalidade da produção da agricultura familiar da região ${ }^{43}$.

Nesse processo, podem ser resgatados alimentos in natura, especialmente frutas e hortaliças que possibilitem cardápios flexíveis, baseados em critérios de diversidade e não somente de quantidade. Tais práticas garantem alimentos mais nutritivos e de menor custo, assim como aproximam os escolares dos ciclos naturais e agrícolas, além de promoverem os negócios dos agricultores familiares locais ${ }^{40}$.

A elaboração de cardápios e o estímulo à produção de alimentos sustentáveis devem estar alinhados com a gestão das compras. Souza ${ }^{44}$ 
destaca a necessidade de manutenção dos contratos de compra da agricultura familiar, que garantam o abastecimento regular.

A qualidade dessa articulação entre gestores tem variado bastante nos contextos locais, sendo os setores de compra apontados como um dos gargalos da efetivação e negociação de condições justas para a compra e o abastecimento da agricultura familiar na alimentação escolar ${ }^{45}$. Ressaltam-se o pouco conhecimento e as diferentes interpretações da Lei $n^{\circ} 11.947 / 2009$ pelos setores de compra das entidades executoras do PNAE. Como exemplo, os critérios de seleção das propostas de venda da agricultura familiar diferem das compras públicas, regidas pela Lei $n^{\circ} 8.666 /$ 1993. De acordo com a Resolução n $26 / 2013$, a prioridade à origem do alimento (local, regional ou nacional, nessa ordem) bem como a preferência por alimentos orgânicos são critérios para o julgamento de propostas, superiores ao preço de venda.

Parece fundamental o acompanhamento da evolução do diálogo entre Entidades Executoras do PNAE e organizações da agricultura familiar, seja no aspecto do planejamento de produção, calendário e diversidade agrícola, seja no aspecto da compreensão das especificidades da nova lei por parte dos setores de compra. Tal acompanhamento permitiria avaliações futuras e continuadas da efetividade do Programa quanto ao alcance de suas diretrizes.

Atualmente, a operacionalização dessas novas diretrizes tem levantado outros desafios que conformam também importantes questões de pesquisa, como o enfrentamento das dificuldades de logística e a aquisição de alimentos pouco processados pela agricultura familiar, bem como o impacto das novas diretrizes do PNAE sobre o desenvolvimento rural sustentável.

A logística exigida pelo PNAE para entrega nas escolas, especialmente nos centros urbanos de maior porte, demanda esquemas complexos e de alto custo. Historicamente, a capacidade de logística na entrega é um trunfo dos grandes distribuidores e atacadistas, que compõem o sistema alimentar convencional. É preciso acompanhar os esforços que estão acontecendo para a superação desse desafio.

A legislação sanitária no Brasil hoje é um dos fatores que limitam o acesso dos consumidores a alimentos processados saudáveis ${ }^{30}$. Nesse sentido, ações protagonizadas por movimentos da Agroecologia e da segurança alimentar e nutricional vêm insistindo em mudanças no regime sociotécnico do processamento de alimentos no Brasil, como uma forma de enfrentamento da questão alimentar no País ${ }^{46,47}$. Os mercados institucionais, como a Alimentação Escolar, demandam a regularização das agroindústrias familiares, comunitárias e artesanais, cujas características não se enquadram em muitas exigências da legislação sanitária, elaborada em consonância com o sistema agroalimentar moderno, que privilegia grandes escalas de produção de alimentos e a concentração do processamento. Acompanhar esse recente processo e a participação do PNAE na facilitação do acesso ao consumo de alimentos processados saudáveis conforma outra questão de pesquisa.

Por fim, o avanço na relação entre cardápios escolares e sustentabilidade depende do envolvimento dos diferentes atores sociais da Alimentação Escolar: nutricionistas, merendeiras, professores, gestores, agricultores e conselheiros de alimentação escolar. Além disso, a prática da sazonalidade pode ainda ser vista como um elemento de educação alimentar e ambiental positivo para toda a comunidade escolar.

As crianças formam seus hábitos alimentares experimentando os alimentos e olhando o que comem sua família, professores e amigos. Para ser bem-sucedido, o cardápio deve ser aceito pelos escolares. Por isso, a dimensão da educação alimentar e nutricional não pode ficar fora da discussão sobre a sustentabilidade promovida por cardápios escolares. A escola tem um importante papel na formação do paladar das crianças ${ }^{40}$. Nesse sentido, a regulamentação do PNAE ressalta que ações educativas abordando o tema alimentação e nutrição e o desenvolvimento de práticas 
saudáveis de vida, na perspectiva da SAN, devem perpassar o currículo escolar ${ }^{4,5}$. Atividades pedagógicas - como visitas de sensibilização às propriedades orgânicas, almoços comunitários com os agricultores, fóruns de economia solidária, palestras sobre a qualidade dos alimentos orgânicos e discussões nas escolas, envolvendo técnicos das Entidades Executoras, das associações de produtores e a comunidade escolar -, são algumas ações a serem fortalecidas no ambiente escolar. Também se destaca o papel das organizações populares urbanas, igrejas e associações de bairro, as quais podem exercer uma pressão social importante a favor de políticas públicas sociais ${ }^{48}$.

Além disso, a inserção dessa proposta pode direcionar uma oportunidade pedagógica interessante, alinhada com a iniciativa das Escolas Promotoras de Saúde ${ }^{49}$ e com os Parâmetros Curriculares Nacionais $(P C N)^{50}$. Noções de educação alimentar e nutricional, de ecologia, de cidadania e direito ao alimento, além de aspectos ambientais e sociais, podem ser trabalhadas na escola, a partir da perspectiva da produção familiar orgânica, formando cidadãos mais conscientes ${ }^{48,51}$. Destaca-se que muitas crianças que frequentam a rede pública de educação são filhos de ex-agricultores familiares, que deixaram suas terras e partiram para as cidades em busca de melhores perspectivas. Oferecer o alimento da agricultura familiar é uma forma de retorno social para esses cidadãos que perderam mais do que suas terras ${ }^{41}$.

\section{CONSIDERAÇÕ ES FINAIS}

As diretrizes do PNAE - ao indicarem uma pauta de alimentos in natura, diversificados, sazonais, preferencialmente orgânicos e que respeitem preferências, hábitos e tradições alimentares locais -, dialogam com as premissas da PNSAN, centradas no apoio a sistemas de produção de alimentos de base ecológica, promotores de justiça social e do desenvolvimento local sustentável.

No entanto, apesar do avanço dessa Política, a elaboração dos cardápios no PNAE ainda é vinculada ao sistema agroalimentar convencional. Portanto, a nova agenda exige o fortalecimento de estratégias estruturais e educativas que possibilitem resgatar hábitos alimentares e produzir alimentos compatíveis com essas diretrizes. Assumir cardápios sazonais que levem em conta a diversidade de alimentos regionais com regras sanitárias específicas, assim como realizar o mapeamento de agricultores ecológicos, são ações que podem nortear a demanda e a oferta programada desses alimentos.

Para que os cardápios escolares dialoguem com a sustentabilidade, é preciso encarar alguns desafios relativos à gestão da compra e da logística, cobrar apoio governamental ao Programa, fomentar seu controle social pelos diferentes atores da comunidade escolar, bem como promover a sensibilização e educação continuada de técnicos e profissionais da área de alimentação escolar, além dos especialistas na academia.

As experiências exitosas devem ser seguidas, assim como novas pesquisas com base na análise dessas diretrizes devem ser incentivadas, para possibilitar o fortalecimento do Programa.

\section{COLABORADORES}

AA SOUSA colaborou no desenho e concepção do artigo; redação e revisão crítica final do texto. APF SILVA colaborou na redação, revisão de literatura e da estruturação final do texto. E AZEVEDO e MO RAMOS colaboraram na concepção do artigo, redação crítica e revisão final do texto.

\section{REFERÊ NCIAS}

1. Brasil. Ministério da Educação. Fundo Nacional de Desenvolvimento da Educação. Alimentação escolar, histórico. Brasília: FNDE; 2009 [acesso 2013 abr 19]. Disponível em: http://www.fnde.gov.br/ programas/alimentacao-escolar/alimentacaoescolar-historico

2. Brasil. Conselho Nacional de Segurança Alimentar e Nutricional. Documento-base para a III Conferência Nacional de Segurança Alimentar e Nutricional. Brasília: Consea; 2011. 
3. Brasil. Ministério da Saúde. Lei $n^{\circ} 11.346$, de 15 de setembro de 2006. Cria o Sistema Nacional de Segurança Alimentar e Nutricional - SISAN com vistas em assegurar o direito humano à alimentação adequada e dá outras providências. Diário Oficial da União. 200615 set.

4. Brasil. Ministério da Educação. Fundo Nacional de Desenvolvimento da Educação. Resolução n 38 de 16 de julho de 2009. Dispõe sobre o atendimento da alimentação escolar aos alunos da educação básica no Programa Nacional de Alimentação Escolar (PNAE). Diário Oficial da União. 200917 jul.

5. Brasil. Ministério da Educação. Fundo Nacional de Desenvolvimento da Educação. Resolução n 26 de 17 de junho de 2013. Dispõe sobre o atendimento da alimentação escolar aos alunos da educação básica no âmbito do Programa Nacional de Alimentação Escolar (PNAE). Diário Oficial da União. 2013 18 jun.

6. Brasil. Ministério da Saúde. Secretaria de Atenção à Saúde. Política Nacional de Alimentação e Nutrição. Brasília: Ministério da Saúde; 2012 [acesso 2013 maio 6] Disponível em: http://189.28.128. 100/nutricao/docs/geral/pnan2011.pdf

7. Brasil. Ministério do Desenvolvimento Agrário. Plano Nacional de Promoção das Cadeias de Produtos da Sociobiodiversidade. Brasília: Ministério do Desenvolvimento Agrário; 2009.

8. Schmitz BAS, Heyde MEDV, Cintra IP, Franceschini S, Taddei JAC, Sigulem D. Políticas e programas governamentais de alimentação e nutrição no Brasil e sua involução. Cad Nutr. 1997; 13:39-54.

9. Spinelli MAS, Canesqui AM. O programa de alimentação escolar no estado de Mato Grosso: da centralização à descentralização (1979-1995). Rev Nutr. 2002; 15(Supl.1):105-17. http://dx.doi.org/10.15 90/S1415-52732002000100011

10. Galeazzi MAM, Chaim NA. Diagnóstico da alimentação escolar em Campinas. In: Instituto Nacional de Estudos e Pesquisas Educacionais. Em Aberto. Brasília: INEP; 1995. p.106-15.

11. Abreu M. Alimentação escolar na América Latina: programas universais ou focalizados/políticas de descentralização. In: Instituto Nacional de Estudos e Pesquisas Educacionais. Em Aberto. Brasília: INEP; 1995. p.21-32.

12. Galeazzi MAM, Vianna RPT, Zabotto CB. Aplicação das recomendações da Fundação de Assistência ao Estudante na gestão do Programa de Alimentação Escolar. In: Instituto Nacional de Estudos e Pesquisas Educacionais. Em Aberto. Brasília: INEP; 1995. p.116-23.

13. Belik W, Chaim NA. O programa nacional de alimentação escolar e a gestão municipal: eficiência administrativa, controle social e desenvolvimento local. Rev Nutr. 2009; 22(5):595-607. http://dx.doi. org/10.1590/S1415-52732009000500001

14. Real LCV, Schneider S. O uso de programas públicos de alimentação na reaproximação do pequeno produtor com o consumidor: o caso do programa de alimentação escolar. Estud Debate. 2011; 18(2):57-79.

15. Téo CRPA, Monteiro CA. Marco legal do programa nacional de alimentação escolar: uma releitura para alinhar propósitos e prática na aquisição de alimentos. Rev Nutr. 2012; 25(5):657-68. http://dx. doi.org/10.1590/S1415-52732012000500010

16. Triches RM, Schneider S. Alimentação escolar e agricultura familiar: reconectando o consumo à produção. Saúde Soc. 2010; 19(4):933-45. http:// dx.doi.org/10.1590/S0104-12902010000400019

17. Brasil. Ministério da Saúde. Guia alimentar para a população brasileira: promovendo a alimentação saudável. Brasília: Ministério da Saúde; 2008 [acesso 2012 nov 30]. Disponível em: http://bvsms.saude. gov.br/bvs/publicacoes/guia_alimentar_populacao_ brasileira.pdf

18. Azevedo E, Rigon SA. Sistema alimentar com base no conceito de sustentabilidade. In: Taddei JA, Lang RMF, Longo-Silva G, Toloni MHA, organizadores. Nutrição em saúde pública. São Paulo: Rubio; 2010. p.543-60.

19. Azevedo E. Alimentação e modos de vida saudável. Saúde Rev. 2004; 13(6):31-6.

20. Comissão Mundial sobre Meio Ambiente e Desenvolvimento. Nosso futuro comum. Rio de Janeiro: Fundação Getúlio Vargas; 1991.

21. Morais LP, Costa ABO. Por novos paradigmas de produção e consumo. Le Monde Diplomatique. 2009 [acesso 2009 dez 5]; 28. Disponível em: http:/ /www.polis.org.br/utilitarios/editor2.0/UserFiles/ File/Notas \% 20 sobre $\% 20$ os \% 2 nnovos $\% 20$ paradigmas.pdf

22. Sachs I. Estratégias de transição para o século XXI: desenvolvimento e meio ambiente. São Paulo: Studio Nobel; 1993.

23. Friedmann H. From colonialism to green capitalism: Social movements and emergence of food regimes. Res Rural Sociol Dev. 2005; 11:227-64.

24. Silva JG. O Progresso técnico na agricultura. In: Tecnologia e agricultura familiar. Porto Alegre: UFRGS; 1999. p.13-50.

25. Caporal FR, Costabeber JA, Paulus G, organizadores. Agroecologia: uma ciência do campo da complexidade. Brasília: Embrapa; 2009.

26. Caporal FR, Costabeber JA. Agroecologia: alguns conceitos e princípios. Brasília: Ministério do Desenvolvimento Agrário; 2004. 
27. Goodman D, Dupuis ME, Goodman MK. Alternative food networks: Knowledge, practice, and politics. Abingdon: Routledge; 2012.

28. Sherwood S, Arce A, Berti P, Borja R, Oyarzun P, Bekkering $E$. Tackling the new materialities: Modern food and counter-movements in Ecuador. Food Policy. 2013; 41:1-10.

29. Ploeg JD van der. Parmalat: um exemplo europeu de um império alimentar. In: Camponeses e impérios alimentares. Porto Alegre: UFRGS; 2008. p.107-132.

30. Cruz FT. Produtores, consumidores e valorização de produtos tradicionais: um estudo sobre qualidade dos alimentos a partir do caso do queijo serrano dos Campos de Cima da Serra-RS [doutorado]. Porto Alegre: Universidade Federal do Rio Grande do Sul; 2012.

31. Darolt MR. Merenda escolar orgânica: uma mudança de hábito saudável. Londrina: Instituto Agronômico do Paraná; 2002 [acesso 2013 mar 26]. Disponível em: http://www.iapar.br/arquivos/File/ zip_pdf/Merenda\%200rg.pdf

32. Carneiro FF, Pignati W, Rigotto RM, Augusto LGS, Rizollo A, Muller NM, et al. Dossiê Abrasco: um alerta sobre os impactos dos agrotóxicos na saúde. Rio de Janeiro: Abrasco; 2012 [acesso 2013 set 12]. Disponível em: http://www.abrasco.org.br/User Files/File/ABRASCODIVULGA/2012/Dossie AGT.pdf

33. Ramos MO. A "comida da roça" ontem e hoje: um estudo etnográfico dos saberes e práticas alimentares de agricultores de Maquiné [dissertação]. Porto Alegre: Universidade Federal do Rio Grande do Sul; 2007.

34. Menasche R, organizador. A agricultura familiar à mesa: saberes e práticas da alimentação no Vale do Taquari. Porto Alegre: UFRGS; 2007.

35. Gabriel CG, Costa LCF, Calvo MCM, Vasconcelos FAG. Planejamento de cardápios para escolas públicas municipais: reflexão e ilustração deste processo em duas capitais brasileiras. Rev Nutr. 2012; 25(3):363-72. http://dx.doi.org/10.1590/ S1415-52732012000300006

36. Woortmann K. Hábitos e ideologias alimentares em grupos sociais de baixa renda. Brasília: Universidade Nacional de Brasília; 1978.

37. Rede Juçara. Alimentação escolar. Juçara no cardápio do lanche nas escolas. REJU. 2011; 2 de 3 [acesso 2013 set 19]. Disponível em: http://www. coletivocatarse.com.br/downloads/reju/revista_ rede_jucara_sustentabilidade_toda.pdf

38. Santilli J. A Lei de Sementes brasileira e os seus impactos sobre a agrobiodiversidade e os sistemas agrícolas locais e tradicionais. Bol Mus Para Emílio
Goeldi Ciênc Hum. 2012; 7(2):457-75. http://dx. doi.org/10.1590/S1981-81222012000200009

39. Pacheco MEL, Schotz V, Rigon AS, Cassarino JP, Leite $\mathrm{CE}$, organizadores. Soberania e segurança alimentar na construção da agroecologia: sistematização de experiências. Grupo de Trabalho em Soberania e Segurança Alimentar da Articulação Nacional de Agroecologia. Rio de Janeiro: FASE; 2010 [acesso 2013 set 16]. Disponível em: http://www. agroecologia.org.br/index.php/publicacoes/ publicacoes-da-ana/publicaoes-da-ana/ agroecologia-e-ssan-pdf/detail

40. Ramos MO. "As crianças estão se sentindo importantes": avanços na alimentação escolar a partir da Lei 11.947/2009 e da compra da agricultura familiar. Rev Trajetória Multicursos. 2011 [acesso 2013 set 19]; (Esp.):4-29. Disponível em: http:// www.facos.edu.br/old/galeria/129072011 032717.pdf

41. Azevedo E. Alimentos orgânicos: ampliando os conceitos de saúde humana, ambiental e social. São Paulo: Senac; 2012.

42. Veiros MB, Proença RPC. Princípios da sustentabilidade na produção de refeições. Nutr Pauta. 2010; 18(102):45-9.

43. Brasil. Ministério do Desenvolvimento Agrário. Alimentação escolar. Brasília: Ministério do Desenvolvimento Agrário; 2013 [acesso 2013 maio 6]. Disponível em: http://portal.mda.gov.br/portal/saf/ programas/alimentacaoescolar/2500755

44. Souza LBB. Organizações da agricultura familiar no Estado de São Paulo e sua experiência de fornecimento para o PNAE. In: Corá MAJ, Belik W, organizadores. Projeto Nutre SP: análise da inclusão da agricultura familiar na alimentação escolar no Estado de São Paulo. Brasília: Ministério do Desenvolvimento Agrário; 2012 [acesso 2013 jun 30]. p.1-104. Disponível em: http://portal.mda.gov.br/ portal/saf/arquivos/view/alimenta-o-escolar/ arquivos-2012/Publica \% C 3\% A7\% C 3\% A30 Nutres\%C3\%830PAULO.pdf

45. Castro CV-A. The school food procurement form 'family farmers' in Rio Grande do Sul (Brazil): An interpretive policy analysis [dissertation]. Netherlands: Wageningen University; 2012.

46. Fórum Brasileiro de Soberania e Segurança Alimentar e Nutricional. Que alimentos (não) estamos comendo? VII Encontro Nacional do FBSSAN, 2013. Porto Alegre: FBSSAN; 2013 [acesso 2014 set 26]. Disponível em: http://rs.caritas.org.br/novo/wpcontent/uploads/2013/07/Carta-Pol\%C3\%A Dticade-Porto-Alegre_FBSSAN.pdf

47. Instituto Sociedade, População e Natureza. Oficina Normas Sanitárias para alimentos de produção artesanal, familiar e comunitária. Brasília: ISPN; 
2012 [acesso 2013 abr 30]. Disponível em: http:// www.ispn.org.br/documentos-e-resultados-daoficina-sobre-normas-sanitarias-para-alimentos-deproducao-artesanal-familiar-e-comunitaria/

48. Azevedo E. O valor nutricional na construção do conceito de alimento saudável: uma discussão a partir dos alimentos orgânicos e da promoção da saúde In: Mialhe F, Pelicioni MCF. Educação e promoção da saúde: teoria e prática. Rio de Janeiro: Santos; 2012. p.257-69.

49. Brasil. Ministério da Saúde. Organização PanAmericana da Saúde. Escolas promotoras de saúde: experiências do Brasil. Brasília: Ministério da Saúde; 2006 [acesso 2013 abr 30]. Disponível em: http:// bvsms.saude.gov.br/bvs/publicacoes/escolas_ promotoras_saude_experiencias_brasil_p1.pdf
50. Brasil. Ministério da Educação. Parâmetros curriculares nacionais: meio ambiente, saúde. Brasília: Secretaria de Educação Fundamental; 1997 [acesso 2013 abr 30]. Disponível em: http://portal.mec. gov.br/seb/arquivos/pdf/livro091.pdf

51. Cunha E, Sousa AA, Machado NMV. A alimentação orgânica e as ações educativas na escola: diagnóstico para a educação em saúde e nutrição. Ciên Saúde Colet. 2010; 15(1):39-49. http://dx.doi.org/ 10.1590/S1413-81232010000100009

Recebido: novembro 19, 2013

Versão final: outubro 31, 2014 Aprovado: novembro 17, 2014 
